\title{
Secondary metabolites in a neotropical shrub: spatiotemporal allocation and role in fruit defense and dispersal
}

Lauren D. Maynard, Heather L. Slinn, Andrea E. Glassmire, Bernal Matarrita-Carranza, Craig D.

Dodson, Trang T. Nguyen, Megan J. Burroughs, Lee A. Dyer, Christopher S. Jeffrey, Susan R.

Whitehead

This is a post-peer-review, pre-copy edit version of an article published in Ecology. The final authenticated version is available online at: https://doi.org/10.1002/ecy.3192.

Copyright by the Ecological Society of America

Suggested Citation: Maynard, L. D., Slinn, H. L., Glassmire, A. E., Matarrita-Carranza, B., Dodson, C. D., Nguyen, T. T., Burroughs, M. J., Dyer, L. A., Jeffrey, C. S., and Whitehead, S. R.. 2020. Secondary metabolites in a neotropical shrub: spatiotemporal allocation and role in fruit defense and dispersal. Ecology 101(12):e03192. 10.1002/ecy.3192. 


\section{$1 \quad$ ABSTRACT $(\max 350$ words)}

2 Deciphering the ecological roles of plant secondary metabolites requires integrative studies that

3 assess both the occurrence patterns of compounds and their bioactivity in ecological interactions.

4 Secondary metabolites have been primarily studied in leaves, but many are unique to fruits and

5 can have numerous potential roles in interactions with both mutualists (seed dispersers) and

6 antagonists (pathogens and predators). We described 10 secondary metabolites of the class

7 alkenylphenols from the plant species Piper sancti-felicis, quantified their patterns of intraplant

8 allocation across tissues and fruit development, and examined their ecological role in fruit

9 interactions. We found that fruit pulp had the highest concentrations and diversity of

10 alkenylphenols, followed by flowers; leaves and seeds had only a few compounds at detectable

11 concentrations. We observed a nonlinear pattern of alkenylphenol allocation across fruit

12 development - increasing as the flowers developed into unripe pulp then decreasing as the pulp

13 ripened. This pattern is consistent with the hypothesis that alkenylphenols function to defend fruits

14 from pre-dispersal antagonists and are allocated based on the contribution of the tissue to the

15 plant's fitness. To assess the impacts of alkenylphenols in interactions with antagonists and

16 mutualists, we performed fungal bioassays, field observations, and feeding experiments with

17 vertebrate dispersers. In fungal bioassays, we found that increasing concentrations of

18 alkenylphenols had a negative effect on the growth of most fungal taxa. In field observations,

19 nocturnal dispersers (bats) removed the majority of infructescences, and diurnal dispersers (birds)

20 removed a larger proportion of unripe infructescences. In feeding experiments, bats had an

21 aversion to alkenylphenols, but birds did not. This aversion observed in bats, combined with our

22 results showing a decrease in alkenylphenols during ripening, suggests that alkenylphenols in fruits

23 represent a trade-off (defending against pathogens but reducing disperser preference). Together, 
24 this research provides a broad overview of the ecological significance of a little studied class of

25 secondary metabolites in seed dispersal and fruit defense. It can also serve as a roadmap for

26 integrating the study of intraplant spatiotemporal allocation patterns with ecological experiments

27 to further our understanding of the evolutionary ecology of plant chemical traits.

29 Keywords: Antagonism; Alkenylphenols; Defense trade-off hypothesis; La Selva Biological Station; Mutualism; Optimal defense theory; Piper sancti-felicis; Specialized metabolites

\section{INTRODUCTION}

One of the most extraordinary features of plants is their biosynthetic capacity to generate

34 diverse secondary metabolites. Secondary metabolites (also referred to as specialized metabolites),

35 are thought to function primarily in plant interactions with the abiotic and biotic environment.

36 They can have broad consequences for the ecology and evolution of plants, consumers, and entire

37 communities (Kessler and Kalske 2018). However, only a small fraction of secondary metabolites

38 have been structurally elucidated, and an even smaller fraction have any ascribed function. A key

39 step toward understanding the ecological roles of secondary metabolites is to describe the

40 intraplant spatiotemporal patterns of secondary metabolite occurrence (i.e. where and when are

41 they occuring in the plant). This variation may be a crucial, yet overlooked, function for plant

42 fitness (reviewed in Moore et al. 2014). While most ecological studies of secondary metabolites

43 have focused on leaves, many compounds are produced primarily in other organs, such as fleshy

44 fruits.

Fleshy fruits function primarily to attract animal mutualists who will effectively transport

46 seeds away from the parent plant. However, the same rewards that attract dispersers are a resource 
47 for many antagonists, including pathogens and seed predators. The high risk of attack of fruits,

48 combined with their high fitness value, leads to predictions based on plant defense theory that

49 fruits should be heavily defended (McKey 1974, Rhoades and Cates 1976, Zangerl and Rutledge

50 1996). Indeed, fruits often have higher diversity and concentrations of secondary metabolites

51 compared to leaves (Herrera 1982, Cipollini and Levey 1997, Çirak and Radušienè 2007,

52 Whitehead et al. 2013, Whitehead and Bowers 2014). Many secondary metabolites in fruits may

53 also serve as frugivore attractants or function to mediate frugivore behavior and physiology (Thies

54 et al. 1998, Cipollini 2000, Rodríguez et al. 2013, Baldwin and Whitehead 2015). Understanding

55 the functional significance of fruit secondary metabolites could provide valuable insight into

56 ecological processes, including seed dispersal — a critical ecological process that determines plant

57 distribution and abundance (Cipollini and Levey 1997, Tewksbury 2002).

Fruits are complex organs, and different tissues and developmental stages likely experience

59 an array of selective pressures and constraints that may shape their chemical traits. Studies that

60 have compared the within-fruit spatial distribution of secondary metabolites (e.g. pulp vs seeds)

61 have shown that the composition of secondary metabolites in these tissues can be highly variable

62 and tissue-specific (Cappelletti et al. 1992, Barnea et al. 1993, Whitehead and Bowers 2013,

63 Whitehead et al. 2013, Beckman 2013, Kolniak-Ostek 2016, D’Abrosca et al. 2017). For example,

64 capsaicin in chilies occurs only in fruits and is highly concentrated in the placental tissue

65 surrounding seeds (Iwai et al. 1979, Fujiwake et al. 1982). Secondary metabolite composition, at

66 least in domesticated fruits, can also change dramatically during development (Hall et al. 1987,

67 Kulkarni 2005, Zhang et al. 2010, Tohge et al. 2014), but these patterns, and the potential to inform

68 our understanding of ecological function, are less explored in wild fruits.

69 There are different hypothesized adaptive functions of fruit secondary metabolites that 
generate different predictions for changes in their allocation during fruit development. Here, we

71 offer three hypotheses that explain the allocation of secondary metabolites in fruit development

72 based on function: manipulation of mutualists, defense allocated by risk, and defense allocated by

73 fitness (Table 1). First, a number of adaptive hypotheses explaining the occurrence of fruit

74 secondary metabolites (e.g. gut retention time hypothesis, directed toxicity hypothesis, and

75 attraction/repulsion hypothesis; Cipollini and Levey 1997) are united by the idea that certain

76 secondary metabolites may function primarily to mediate interactions with vertebrate consumers

77 of ripe fruits. For example, the gut retention time hypothesis (Cipollini and Levey 1997, Baldwin

78 and Whitehead 2015) posits that certain secondary metabolites in fruits could function to mediate

79 the passage rate of seeds in frugivore guts, thereby impacting dispersal distance and the exposure

80 of seeds to gut conditions. If manipulation of disperser behavior or physiology is the primary

81 adaptive function driving the patterns of occurrence of a particular secondary metabolite, we would

82 predict maximum allocation to that metabolite in ripe fruits: the stage of fruit development with

83 the greatest amount of interaction with frugivores.

Alternatively, fruit secondary metabolites may function primarily to defend fruits against

85 insect pests and microbial pathogens, as posited by the defense trade-off hypothesis (Cipollini and

86 Levey 1997, Dyer et al. 2001, Cazetta et al. 2008, Whitehead and Bowers 2014, Whitehead et al.

87 2016). Our second and third hypotheses both explain allocation patterns in fruits based on this

88 idea. In both cases, the same secondary metabolites that defend fruits may also deter beneficial

89 dispersers, leading to costly trade-offs when they are produced in ripe fruit pulp. Thus, if a

90 secondary metabolite functions primarily in defense, we would expect the concentrations to

91 decline with final ripening. However, the overall patterns during development may depend on the

92 costs and benefits of defense. 
Optimal defense theory predicts that plants allocate chemical defenses across different

94 tissues based on the cost of defending that tissue, the relative risk of attack, and the fitness 95 consequences of tissue loss (McKey 1974, Rhoades and Cates 1976). Depending on the relative

96 importance of these factors, this could lead to various predictions for defense allocation during

97 fruit development. If risk of attack is the main driver of allocation, we would predict that defenses

98 are highest in immature fruits, which are composed of rapidly expanding and highly nutritious

99 tissues that are not yet protected by physical defenses (e.g. a tough exocarp). The same general

100 pattern is seen in leaves, where young leaves experience much higher rates of damage compared

101 to mature leaves and are often more highly-defended (Kursar and Coley 1991, McCall and Fordyce

102 2010, Barton et al. 2019). If instead the fitness consequences of tissue loss are the main driver of

103 allocation, we would predict a non-linear change in fruit secondary metabolites during

104 development. Early in development, the metabolic investment in a fruit is still minimal, but as

105 fruits mature, their fitness value increases. The negative fitness costs of consumption would peak

106 immediately before fruit maturity: the plant has invested heavily in producing fruit, but the seeds

107 are not yet viable. Once seeds mature, the fitness consequences of consumption can shift from a

108 net fitness loss to a net gain (depending on the consumer), and maintaining high levels of defenses

109 could limit dispersal. Thus, in this scenario, we would predict that the concentration of secondary

110 metabolites will increase over development, peak before maturation, and then decrease as fruits

111 enter the final ripening stage and are ready for dispersal (Table 1).

112 The hypotheses described above rest on the assumption that secondary metabolites in fruits

113 provide adaptive benefits in biotic interactions and are specifically regulated in plants according

114 to their fitness costs and benefits. However, it is also critical to consider that the occurrence

115 patterns of many secondary metabolites may be the result of neutral or non-adaptive processes. At 
116 least two non-adaptive processes may contribute to spatial and developmental patterns. First,

117 certain secondary metabolites in fruits may be present due to strong selection for defense of leaves

118 and other plant parts, combined with physiological constraints on their exclusion from fruit tissues

119 (Swain 1977, Eriksson and Ehrlén 1998). In this case, we might expect that: 1) secondary

120 metabolites should be more diverse and abundant in leaves than in fruits, and 2) concentrations in

121 fruits and leaves should be correlated. These predictions have not been supported in other systems

122 (Whitehead and Bowers 2013), but could be true for other plant species or classes of compounds.

123 Second, temporal variation in secondary metabolite abundance during fruit development may

124 occur as a passive consequence of other physiological processes, rather than the specific adaptive

125 regulation of particular compounds. For example, a reduction in the concentration of a compound

126 during ripening could be simply due to enzymatic degradation that occurs during fruit softening

127 (Brady 1987). In this case, as with any non-adaptive scenario, there may be limited or neutral

128 consequences of fruit secondary metabolites in fruit defense or seed dispersal. Thus, furthering our

129 understanding of the evolutionary ecology of secondary metabolites in fruits requires a

130 combination of descriptive documentation of spatiotemporal occurrence patterns and ecological

131 experiments to examine the bioactivity of fruit secondary metabolites in interactions with fruit

132 consumers - including both mutualists and antagonists.

133 In this study, we combine structure elucidation of secondary metabolites, quantitative

134 descriptions of spatiotemporal chemical variation, field observations, fungal bioassays, and

135 behavioral experiments with birds and bats to provide a broad overview of the evolutionary

136 ecology of fruit secondary metabolites in Piper sancti-felicis Trel. (Piperaceae). Piper sancti-

137 felicis is a widespread and abundant neotropical shrub and was chosen for a case study because it

138 fruits abundantly throughout the year and represents a dietary staple for bats and birds (Fleming 
2004, Thies and Kalko 2004). Little was known about the secondary chemistry of this species, and

140 our initial analyses suggested infructescences were dominated by compounds structurally related

141 to alkenylphenols described from other species of Piper (Orjala et al. 1998, Valdivia et al. 2008,

142 de Oliveira et al. 2012, Yang et al. 2013, Varela et al. 2017, Yoshida et al. 2018). This study had

143 four specific objectives: 1) to elucidate the structures of the major alkenylphenol compounds

144 present in P. sancti-felicis; 2) to assess the extent to which spatial patterns of alkenylphenol

145 occurrence across tissues (leaves, flowers, unripe fruit pulp, ripe fruit pulp, and seeds) and

146 temporal patterns during fruit development are consistent with different hypothesized functions of

147 fruit secondary metabolites (Table 1);3) to test the effects of alkenylphenols in interactions with

148 fruit-associated fungi (antagonists); and 4) to test the effects of fruit alkenylphenols in interactions

149 with vertebrate seed dispersers (mutualists). Together, these investigations provide an overview of

150 the ecological significance of a group of secondary metabolites, demonstrate the value of using

151 intraplant spatiotemporal variation to understand ecological roles, and, more broadly, contribute a

152 holistic understanding of the functions of secondary metabolites in biotic interactions, including

153 fruit defense and seed dispersal.

\section{METHODS}

\section{Study site and system}

All plant collection and experiments were conducted at La Selva Biological Station 158 (LSBS), Heredia Province, Costa Rica. The station is managed by the Organization for Tropical 159 Studies (OTS) and comprises approximately 1600 ha of tropical wet forest. The site has high 160 diversity of the genus Piper, and hosts over 60 species (OTS 2020). Piper is one of the largest 161 genera of flowering plants, containing well over 1,000 species. The greatest diversity of Piper is 
162 found in the neotropics and lowland tropical forest sites, such as LSBS (Gentry 1990). The genus

163 has distinctive inflorescences (spikes containing hundreds of small, reduced flowers along a

164 rachis), and each flower matures into a single-seeded drupelet, creating an infructescence (Greig

165 2004; Fig. 1). For most species of Piper, all fruits on an infructescence mature simultaneously and 166 are dispersed as a single unit. Previous investigations into the genus have described the presence 167 of a broad range of secondary metabolites in leaves, including amides, alkaloids, lignans, terpenes, 168 and steroids (Dyer et al. 2004). Structurally-related compounds to the alkenylphenols in P. sancti169 felicis that have been described from several other species of Piper and have known antifungal, 170 antimicrobial, and cytotoxic properties (Valdivia et al. 2008, Yang et al. 2013). Yet, the occurrence 171 of alkenylphenols in P. sancti-felicis and their ecological significance was, to our knowledge, 172 previously undescribed.

173 The primary dispersers of the infructescences of Piper in neotropical forests are a group of 174 bats in the genus Carollia (Phyllostomidae), which depend on the infructescences as a year-round 175 staple in their diet (Fleming 2004, Maynard et al. 2019). Although species of Carollia are the 176 dominant dispersers, several species of birds also consume the infructescences of Piper, including 177 tanagers (Thraupidae), sparrows (Emberizidae), manakins (Pipridae), toucans (Ramphastidae), 178 cuckoos (Cuculidae), pigeons and doves (Columbidae; Palmeirim et al. 1989, Thies and Kalko 179 2004). After consumption, the seeds passed by both bats and birds are viable (Palmeirim et al. 180 1989). However, the two groups of dispersers handle the infructescences differently. Birds 181 typically consume infructescences at the plant, stripping the pulp and seeds and leaving the rachis 182 (Appendix S1: Fig. S1). Bats use a combination of echolocation and olfaction to locate ripe 183 infructescences, which readily abscise from the plant (Thies et al. 1998). They collect the entire 184 infructescence and carry it to a roost for consumption (Fleming 2004; Appendix S1: Fig. S2). 
185 Furthermore, birds tend to defecate while perched, whereas Phyllostomid bats defecate more often

186 during flight (Charles-Dominique 1986). Thus, seeds consumed by bats may be moved further

187 where they may not be shaded or outcompeted by the parent plant (Levey 1987, Thies and Kalko

188 2004). These differences in handling behaviors, as well as infructescence removal rate and

189 dispersal distance, likely all play a role in the relative seed dispersal effectiveness of birds versus

190 bats (Schupp et al. 2010).

\section{Structure elucidation of alkenylphenols in Piper sancti-felicis}

For structure elucidation of alkenylphenols, unripe and ripe infructescences were collected

193 from approximately 20 individuals of $P$. sancti-felicis occurring in and around the lab clearing at

194 LSBS during June-August 2011. Approximately 200 infructescences were oven-dried at $50^{\circ} \mathrm{C}$ for

$19548 \mathrm{~h}$, ground to a fine powder in a coffee grinder, and transported to the University of Nevada,

196 Reno. An analysis of the crude ${ }^{1} \mathrm{H}-\mathrm{NMR}$ extracts of the infructescences was performed first. The

197 major components were further fractionated using flash column chromatography and preparatory

198 TLC on silica gel using mixtures of hexanes and ethyl acetate, followed by detailed 1D and 2D

$199{ }^{1} \mathrm{H}-,{ }^{13} \mathrm{C}-\mathrm{NMR}$, and EI-MS analysis.

\section{Quantification of alkenylphenols across tissues and developmental stages}

201 To examine variation in alkenylphenols across tissues and developmental stages (Objective

202 2), one branch with fruits spanning a range of developmental stages (one ripe infructescence, two

203 unripe infructescences, two inflorescences, and one developing inflorescence; Fig. 1) was

204 collected from each of 21 P. sancti-felicis individuals ( $n=21$ ), during June-July 2017 and June-

205 July 2018. Similar to other species of Piper, infructescences of $P$. sancti-felicis ripen in the 206 afternoon and are typically removed by bats the first night they are ripe (Fleming 2004). Thus, 
each branch was collected in the afternoon, usually between $1300 \mathrm{~h}$ and $1600 \mathrm{~h}$, so that it included

208 a ripe infructescence that had matured on that day. Mature, fully expanded leaves from the

209 branches were also collected. Each sample was dried in a separate envelope in the field with silica,

210 transported to Virginia Tech, and further lyophilized prior to alkenylphenol extractions.

211 To separate reproductive tissues (i.e. pulp, seeds, and rachis), the dried samples were

212 processed through stainless steel mesh sieves $(0.01 \mathrm{~mm}$ or $0.0075 \mathrm{~mm}$, depending on sample stage

213 and seed size). Seeds were separated from the pulp for both ripe and unripe infructescences.

214 However, only seeds from ripe infructescences were able to be fully cleaned of pulp; thus, only

215 ripe seeds were analyzed. Dried leaves were ground whole. All samples were extracted and

216 analyzed by GC-MS using a process similar to that inWhitehead et al. (2013) and Aziz et al. (2017).

217 Additional methodological details are provided in Appendix S2.

218 Effects of alkenylphenols on fruit-associated fungi (antagonists)

219 To assess whether alkenylphenols that occur in $P$. sancti-felicis have a potential defensive

220 role against fruit-associated fungi (Objective 3), we conducted a microdilution assay in September

2212018 using methods modified from Zgoda and Porter (2001). To extract large quantities of

222 alkenylphenols, ripe infructescences of $P$. sancti-felicis were locally collected at LSBS, oven dried

223 at $60^{\circ} \mathrm{C}$, and ground. A scaled-up version of the extraction procedure described above was used,

224 beginning with a $10 \mathrm{~g}$ aliquot of dried plant material.

225 Three of the most common fungal taxa were selected from P. sancti-felicis seed fungi

226 cultures (Slinn, unpublished data): Microdochium lycopodinum, Fusarium A, and Fusarium B

227 (Appendix S4: Table S4). Fungi were initially cultured on 2\% malt extract agar (Thermo Fisher

228 Scientific Oxoid Malt Extract) and plated at $26^{\circ} \mathrm{C}$ for 6-7 d. Mycelia were harvested from the plate

229 by adding $1 \mathrm{~mL}$ of sterile water and probing the culture with the end of a tip to dislodge fungi. 
230 Fungi were stored in a sterile microcentrifuge tube at $4^{\circ} \mathrm{C}$ until needed. For details on DNA 231 extraction, PCR and sequencing see Appendix S2.

232 BLAST was used to align sequences to taxa in the UNITE v8.2 database which features

233 additional quality control checks for fungi deposited in GenBank (Altschul et al. 1990, Kõljalg et

234 al. 2005, accessed 28 February 2020). Taxa were assigned to ecological guilds using the FUNGuild

235 database (Nguyen et al. 2016, accessed 14 May 2019). Two of the three taxa were classified to the

236 genus Fusarium (Fusarium A and B; guilds: endophyte, plant and animal pathogen, wood

237 saprotroph), and the third taxa was classified as Microdochium lycopodinum (guilds: endophyte,

238 plant pathogen; White et al. 1990, Nguyen et al. 2016; Appendix S4: Table S4). Sequences were

239 deposited at the National Center for Biotechnology Information (NCBI) on GenBank under

240 accession numbers MT093652 - MT093654 (Appendix S4: Table S4).

241 To determine if the compounds had an effect on fungal growth, we performed a

242 microdilution assay with eight-serial dilutions. Each well received half of the alkenylphenol extract

243 concentration compared to the previous well, fungal inoculum, $2 \%$ malt extract to provide nutrients

244 for fungal growth, and sterile DI water. The final volume of each well was $200 \mu 1$. The first well

245 received the highest concentration of extract with $5 \mu 1$ at $73.15 \mathrm{mg} / \mathrm{ml}$ in ethanol and an additional

$246195 \mu 1$ of water. Next, the remaining 7 wells received 100ul of sterile DI water. The water and

247 extract in well 1 was mixed by pipetting before $100 \mu 1$ of the $200 \mu 1$ solution was aliquoted into

248 the second well. This process of mixing newly aliquoted extract into $100 \mu 1$ of water in subsequent

249 wells was continued across the wells until the eighth well where the $100 \mu 1$ taken was discarded.

250 Once the wells had the appropriate concentration gradient of alkenylphenols, each well received

$25180 \mu \mathrm{l}$ of $2 \%$ malt extract and $20 \mu \mathrm{l}$ of fungal inoculum at a spore concentration of $10^{6} \mathrm{cells} / \mathrm{ml}$.

252 Thus, the final concentration of extract in the growth media at the highest concentration was 0.91 
$253 \mathrm{mg} / \mathrm{mL}$, approximately equivalent to 0.0003 proportion fresh weight of a ripe infructescence and

$2546.2 \%$ of average alkenylphenol concentration found in one ripe infructescence. A sterile control

255 with no fungi and no alkenylphenol extract was mixed, including $95 \mu 1$ of water, $80 \mu 1$ of $2 \%$ malt

256 extract, and $25 \mu 1$ of $100 \%$ ethanol. A negative control was also included with $20 \mu 1$ of fungal

257 inoculum and no alkenylphenols. These wells then received $95 \mu$ l of water, $80 \mu 1$ of $2 \%$ malt

258 extract, $5 \mu \mathrm{l}$ of $100 \%$ ethanol in addition to the inoculum. To measure absorbance of fungi, a

259 spectrophotometer was used at $450 \mathrm{~nm}$ with 96 well plates. Hyphal growth was measured as the

260 difference in optical density (or absorbance) at 72h minus 0h. Additional methodological details

261 are provided in Appendix S2.

262 Effects of alkenylphenols on seed dispersers (mutualists)

263 To determine if alkenylphenols that occur in P. sancti-felicis impact interactions with

264 mutualistic vertebrate seed dispersers (Objective 4), we paired field observations with flight cage

265 feeding experiments. For the field studies, we collected observational data on the removal of 266 infructescences of $P$. sancti-felicis from natural plant populations. We chose 10 individual plants

267 for monitoring. All plants were at least $30 \mathrm{~m}$ apart in clearings and along trails within $1 \mathrm{~km}$ of the 268 field station. On each plant, we marked and mapped all unripe and ripe infructescences on up to

26911 branches. Each plant was then visited twice daily (at dawn and dusk) during 26 May-31 May 2702009 , and we recorded all nocturnal and diurnal removal events for unripe and ripe infructescences

271 on marked branches. In addition, to further describe the bird species that use plants of $P$. sancti272 felicis, we conducted focal observations of six individual plants during 5 July-10 July 2018. 273 Visiting bird species and their behavior (i.e. frugivory, gleaning, calling, etc.) were recorded 274 (Appendix S4: Fig. S2). 
To better understand vertebrate responses to the compounds, we conducted feeding trials

276 in a controlled flight cage setting with the dominant consumers of the infructescences of Piper.

277 One representative species was chosen from each group of dispersers: Seba's Short-tailed Bat

278 (Carollia perspicillata Linnaeus, 1758) and Passerini's Tanager (Ramphocelus passerinii

279 Desmarest, 1805; Appendix S1: Fig. S1 \& S2). Feeding trials were conducted during January-

280 March 2018. An experimental diet of mashed bananas and agar was used, which allowed us to test

281 the effects of alkenylphenols on animal preference without the confounding effects of natural

282 variation in alkenylphenols found in infructescences of Piper. The amount of food provided was

283 equivalent to the fresh weight of one ripe infructescence of $P$. sancti-felicis (approximately $3 \mathrm{~g}$ ).

284 For the treatment diet, $1 \mathrm{~mL}$ of alkenylphenol extract was added at an estimated concentration of

$28514.6 \mathrm{mg} / \mathrm{mL}$ (0.0049 proportion fresh weight). For the control diet, $1 \mathrm{~mL}$ of ethanol was applied.

286 All ethanol was evaporated before trials began by allowing diet to air-dry at room temperature

$287\left(\sim 26^{\circ} \mathrm{C}\right)$. For each choice test, one dish each of control and treatment diet were presented

288 simultaneously to each animal (bats $N=16$, birds $N=10$ ) for between one and four trials that

289 occurred over consecutive nights (bat trials $N=58$ ) or days (bird trials $N=27$ ). Each dish was pre-

290 weighed and then placed in the flight cage on separate trays to account for any food displaced from

291 the dish but not consumed. Bat trials began at $1800 \mathrm{~h}$ and bird trials began at $0600 \mathrm{~h}$. Animals were

292 checked every 30-60 min. After the animal had participated by consuming some portion of either

293 diet, the dishes were removed and weighed to determine the amount eaten from each dish. Any

294 food found in the trays was added to the respective dish. Additional methodological details are

295 provided in Appendix S2.

296 Statistical analyses 
All analyses were performed in R v3.6.1 (R Core Team 2020). Linear models, chi-squared 298 analyses, and paired t-tests were performed using the base package, beta-regressions were 299 performed using the package betareg v3.1-2 (Zeileis et al. 2019), estimated marginal means were 300 performed using package emmeans v1.3.5.1 (Lenth et al. 2019), AIC model comparisons were 301 performed using package AICcmodavg v2.2-2 (Linden 2019), analysis of variance (ANOVA) was 302 performed using package car v3.0-3 (Fox et al. 2019), and plots were created with package ggplot2 303 (Wickham et al. 2019). All annotated code, data, and metadata are publicly archived at GitHub 304 (https://github.com/ldmaynard/Alkenylphenols_Psf) and will be permanently archived at Dryad 305 Digital Repository upon publication (DOI TBD).

\section{Variation in alkenylphenols across tissue types and stages of development}

To determine how alkenylphenol concentration varied across tissue types, we fit the data to a beta-regression. The response variable was the proportion dry weight of total alkenylphenols

309 (summed across all detected compounds). Tissue type was a categorical predictor with five levels:

310 leaves, late flowers (stage 4), late unripe pulp (stage 2), ripe pulp (stage 1), and ripe seeds.

311 Estimated marginal means were computed for tissue type.

312 To determine how alkenylphenol concentration changed during fruit development and to 313 assess support for linear and non-linear patterns (Table 1), we fit the data to two beta-regression 314 models: one linear and one nonlinear (i.e. including a quadratic term). The proportion dry weight 315 of total alkenylphenols was the response and developmental stage was a continuous predictor 316 variable (as described in Fig. 1). AIC model comparison was used to select the model of best fit.

\section{Effects of alkenylphenols on fruit-associated fungi (antagonists)}

318 To determine the effect of alkenylphenol concentration and species of fungi on fungal 319 growth, we fit the data to a linear model (LM). The response variable was the difference in 
320 absorbance values of wells containing fungi, measured in average optical density (OD), at $72 \mathrm{~h}$

321 minus $0 \mathrm{~h}$, averaged across triplicate readings taken from each well. The predictor variables were

322 fungal taxa, alkenylphenol concentration in the growth media, and the interaction between the two.

323 AIC model comparison was used to compare the full model to all possible component models. A

324 two-way ANOVA was performed on the model of best fit (full model), which indicated a

325 significant interaction between the species of fungi and concentration of alkenylphenols. Based on

326 this result, the data were analysed separately for each fungi, using only concentration of

327 alkenylphenols as a predictor variable.

\section{Effects of alkenylphenols on seed dispersers (mutualists)}

329 To examine the temporal differences in removal of unripe and ripe infructescences in our

330 field observational study, a chi-squared analysis was used to test for independence between

331 ripening stage and removal period in predicting the number of infructescences removed. To

332 determine the effect of alkenylphenol presence on disperser response in our feeding trials, we

333 performed paired t-tests, conducted separately for birds and bats, comparing the total amount of

334 control eaten versus total amount of treatment eaten by each animal in the behavioral trials.

\section{RESULTS}

337 Structure elucidation of alkenylphenols in Piper sancti-felicis

338 Analysis of the crude ${ }^{1} \mathrm{H}-\mathrm{NMR}$ extracts of the infructescences revealed the presence of 339 para-alkenylphenols due to characteristic $\mathrm{AB}$ sets of coupled doublets in aromatic region (6-7ppm, $340 J=8.5-9.0 \mathrm{~Hz})$, multiplets in the alkene region $(-\mathrm{C} \underline{H}=\mathrm{C} \underline{H}-5.4-4.5 \mathrm{ppm})$, and characteristic 341 aliphatic resonances of a long-chain hydrocarbon $\left[\left(\mathrm{C}_{2}\right)_{\mathrm{n}} 1.2 \mathrm{ppm}\right.$ and $\mathrm{CH}_{3} 0.88$ ppm] (Fig. 2). 342 GC-MS analysis revealed the presence of up to 10 distinct chromatographic peaks corresponding 
343 to compounds A-J (Appendix S3: Fig. S1). Compound F $\left(\mathrm{R}_{\mathrm{t}}=13.6\right)$ was the dominant peak in the

344 extract with compounds $\mathrm{B}$ and $\mathrm{D}(\mathrm{Rt}=12.4$ and 12.9) as the other major components. Analysis of

345 the mass spectra of all components suggested para-alkenylphenol in all cases based upon dominant

346 fragmentation to the hydroxytropilium ion $(\mathrm{m} / \mathrm{z}=107)$ and compared favorably to literature data

347 for other alkenylphenols that have been isolated from other species of Piper (Vieira et al. 1980,

348 Galinis and Wiemer 1993, Jinno and Okita 1998, Li et al. 2008, Valdivia et al. 2008, Yang et al.

349 2013, Rajeev and Jain 2014, Dung et al. 2015, Yoshida et al. 2018). Further analysis of the

350 molecular ion of these peaks suggested that the compounds A, B, E, F, I and J were phenols with

$351 \mathrm{C}_{12}(\mathrm{~A}, \mathrm{~B}), \mathrm{C}_{14}(\mathrm{E}, \mathrm{F}), \mathrm{C}_{16}(\mathrm{I}, \mathrm{J})$ para-alkenyl substituents containing one unit of unsaturation

$352\left(\mathrm{C}_{\mathrm{n}} \mathrm{H}_{2 \mathrm{n}-2}\right)$. Analysis of the molecular ion of compounds $\mathrm{C}, \mathrm{D}, \mathrm{G}$ and $\mathrm{H}$ demonstrated that the para-

353 substituent was a doubly unsaturated dienyl chain of the $\mathrm{C}_{12}(\mathrm{C}$ and $\mathrm{D}) \mathrm{C}_{14}(\mathrm{G}$ and $\mathrm{H})$ series.

354 Isomeric relationships between compound $\mathrm{A}$ and $\mathrm{B}, \mathrm{E}$ and $\mathrm{F}$, and $\mathrm{I}$ and $\mathrm{J}$ suggested that these

355 compounds only differed by the double bond position in the mono-unsaturated para-substituent.

356 The major components were further fractionated using flash column chromatography and

357 preparatory TLC on silica gel using mixtures of hexanes and ethyl acetate. Detailed 1D and 2D

$358{ }^{1} \mathrm{H}-,{ }^{13} \mathrm{C}-\mathrm{NMR}$, and EI-MS analysis of the major component were strongly consistent with the

359 structure of a $p$-alkenylphenol. Double bond position was tentatively assigned in the mono-

360 unsaturated series (A, B, E, F, I and J) based upon EI-MS fragmentation and comparisons to the

361 literature. EI-MS analysis was consistent with the $\Delta^{3^{\prime}, 4^{\prime}}$ position of the double bond for compounds

$362 \mathrm{~A}, \mathrm{E}$, and I and the $\Delta^{4^{\prime}, 5^{\prime}}$ position for compounds B, F, and J. Comparison of all spectral data to

363 known alkenylphenols that have been previously isolated from other Piper species strongly

364 supported the structures of E and I, and supported the proposed structure of the major component

365 F by comparison (Vieira et al. 1980, Yoshida et al. 2018). Double bond position and 
stereochemistry of the doubly unsaturated components $(\mathrm{C}, \mathrm{D}, \mathrm{G}$, and $\mathrm{H})$ in the series could not be

367 unequivocally established based upon NMR and EI-MS analysis. Full structural characterization

368 data for $\mathrm{F}$ and tentative assignments of A-E and G-J are reported in the supplementary information

369 (Appendix S3).

370 Variation of alkenylphenols across tissue types and stages of development

371 Alkenylphenols were abundant in unripe and ripe fruit pulp, present in flowers, and almost

372 undetectable in leaves and seeds (Fig. 3). All 10 compounds were found in flowers and fruit pulp,

373 nine were found in developing flowers, and only two were detected in seeds and leaves

374 (compounds B and F; Appendix S4: Fig. S1 \& Table S1). Our statistical analyses showed that pulp

375 had higher concentrations of alkenylphenols compared to other tissues, including leaves, seeds,

376 and late flowers. The average total concentration of alkenylphenols in unripe pulp was $1.5 \mathrm{x}$ higher

377 than ripe pulp, 2.6x higher than flowers, 36.2x higher than seeds, and 534.9x higher than leaves

378 (Fig. 3, Appendix S4: Fig. S2).

When examining alkenylphenol concentration across reproductive structure developmental

380 stages, AIC model comparison indicated that the nonlinear model (with the quadratic term) was a

381 better fit compared to the linear model (dAICc $=12.25$; Appendix S5: Table S1), and the quadratic

382 term was significant $(P<0.001)$, supporting a non-linear pattern in alkenylphenol concentration

383 during development that peaked just before ripening. Developmental stage was also a significant

384 predictor of alkenylphenol concentration across reproductive structure development $(P=0.023$;

385 Fig. 4). The average concentration of total alkenylphenols in ripe pulp was 1.8, 3.0, and 5.3 times

386 higher compared to late, early, and developing flowers (stages 4, 5, and 6, respectively; Appendix

387 S4: Table S3. However, the average concentration of total alkenylphenols in unripe pulp (stages 2 
388 and 3) were 1.5 and 1.1 times higher compared to ripe pulp (Appendix S4: Table S3).

389 Concentrations of individual compounds are provided in Appendix S4. Effects of alkenylphenols on fruit-associated fungi (antagonists)

The model that best fit the data was the LM that incorporated the interaction between fungal

392 taxa and alkenylphenol concentration (dAICc $=11.4$; Appendix S5: Table S2). The effect of

393 alkenylphenol concentration varied based on fungal species $(F=10.30, P=0.0008$; two-way

394 ANOVA of LM interaction). The growth of Microdochium lycopodinum $(t=-7.03, P=0.0002$,

$\left.395 \mathrm{R}^{2}=0.88 ; \mathrm{LM}\right)$ and Fusarium $\mathrm{A}\left(t=-5.21, P=0.001, \mathrm{R}^{2}=0.80 ; \mathrm{LM}\right)$ experienced clear negative 396 effects when exposed to alkenylphenols; however, Fusarium $\mathrm{B}$ did not $\left(t=-1.00, P=0.35, \mathrm{R}^{2}=\right.$ $3970.13 ; \mathrm{LM})$. For every $1 \mathrm{mg} / \mathrm{mL}$ increase in alkenylphenol concentration, the average absorbance 398 (growth) of Microdochium lycopodinum and Fusarium A decreased by 0.50 OD and 0.43 OD, 399 respectively (Fig. 5).

\section{$400 \quad$ Effects of alkenylphenols on seed dispersers (mutualists)}

401 During field observations, most infructescences of $P$. sancti-felicis were removed at night 402 (presumably bats; 67 infructescences, 91.8\%). We found that diurnal removal events (presumably 403 birds) were more likely to involve unripe infructescences (five unripe infructescences, 83.3\%) 404 whereas nocturnal events were more likely to involve ripe infructescences (59 ripe infructescences, $40582.2 \%)\left(\chi^{2}=14.609, d f=1, P=0.00013\right.$; chi-square test; Appendix S4: Table S5). During flight 406 cage experiments, we found that alkenylphenols had a negative effect on bat feeding response $(t$ $407=3.90, d f=15, P=0.001$; paired t-test $)$, but no detectable effect on birds $(t=0.24, d f=9, P=$ 408 0.81; paired t-test). Bats consumed an average of 2.4 times more control than treatment (Fig. 6a), 409 whereas birds only consumed an average of 1.1 times more control than treatment (Fig. 6b). 


\section{DISCUSSION}

412 Furthering our understanding of the chemical ecology of plant interactions requires

413 integrative studies that incorporate the secondary metabolite structure determination, allocation,

414 and ecological roles. Here, we present a case study of alkenylphenol compounds in a widespread

415 tropical shrub. Using quantitative descriptions of intraplant variation combined with ecological

416 experiments and observations, we put forth potential roles of these compounds in antagonistic and

417 mutualistic interactions. We posited three hypotheses for fruit secondary metabolite allocation

418 patterns: manipulation of mutualists, defense allocated by risk, and defense allocated by fitness

419 (Table 1). We found that alkenylphenols in P. sancti-felicis are dominant in the fruit pulp and

420 flowers, but they were almost absent in leaves and seeds (with lower concentrations and diversity).

421 By quantifying alkenylphenols across fruit development (from developing flower to ripe fruit

422 pulp), we found that the secondary metabolite concentration follows a nonlinear trend, increasing

423 through development until the fruit begins to ripen, then declining in the final ripening stage. This

424 pattern is consistent with the hypothesis that fruit secondary metabolites function primarily as an

425 adaptive defense and are allocated in fruits according to the fitness costs and benefits of

426 consumption. Alternatively, the decline with ripening could be non-adaptive, and instead due to

427 general enzymatic degradation during ripening (Brady 1987). However, the fungal and vertebrate

428 bioassays also supported an adaptive explanation for the observed allocation patterns.

429 Alkenylphenols had clear negative effects on two taxa of potentially pathogenic fungi associated

430 with seeds (Fig. 5), but also had a negative effect on the feeding preferences of bats (specifically

431 C. perspicillata; Fig. 6) — one of the main seed dispersers of P. sancti-felicis (Maynard et al. 2019).

432 Thus, alkenylphenols may represent a trade-off in fruits between defense against antagonists and 
433 attraction of mutualists, and plants may downregulate these compounds during ripening to

434 minimize these trade-offs.

435 Structure elucidation of alkenylphenols in Piper sancti-felicis

436 Alkenylphenols are relatively rare in the plant kingdom, and, aside from Piperacaeae, have

437 been reported in only three other plant families: Anacardiaceae (Franke et al. 2001), Myrsinaceae

438 (Jiménez-Romero et al. 2007), and Myristicaceae (Gonzalez et al. 1996). Alkenylphenol 439 compounds have been identified in seven other species of Piper: P. hispidum (Vieira et al. 1980),

440 P. gibbilimbum (Orjala et al. 1998), P. obliquum (Valdivia et al. 2008), P. malacophyllum (de

441 Oliveira et al. 2012, Varela et al. 2017), P. sarmentosum (Yang et al. 2013), P. dilatatum and $P$.

442 diospyrifolium (Yoshida et al. 2018). These previously described alkenylphenols have been found

443 in several organs of species of Piper, including leaves (Orjala et al. 1998, Valdivia et al. 2008, de

444 Oliveira et al 2012), inflorescences (Valdivia et al. 2008), infructescences (Yoshida et al. 2018),

445 roots (Yoshida et al. 2018), and aerial parts (Yang et al. 2013). However, this is the first study to 446 find alkenylphenol concentration and diversity highest in Piper fruit pulp. Previously described

447 alkenylphenols in Piper species have shown the compounds to exhibit antifungal, antimicrobial, 448 and cytotoxic properties (Valdivia et al. 2008, Yang et al. 2013). However, to our knowledge, this 449 is the first study to explore the adaptive significance of alkenyphenols with a variety of interactors, 450 including the three most abundant fungal taxa found on the seeds (antagonists) and two taxa of the 451 most frequent vertebrate frugivores (mutualists).

\section{Variation of alkenylphenols across tissue types and stages of development}

453 Our results showing alkenylphenols are found largely in fruits and flowers is a key piece 454 of evidence suggesting these compounds function in reproductive structures. This pattern is in 455 direct contrast to predictions that stem from the non-adaptive "physiological constraints" 
456 hypothesis that suggests that certain secondary metabolites in fruits may be present due to strong

457 selection for defense of leaves and other plant parts, combined with physiological constraints on 458 their exclusion from fruit tissues (Swain 1977, Eriksson and Ehrlén 1998). Instead, as 459 alkenylphenols were found primarily in pulp (Fig. 4), their presence in leaves and seeds may be 460 due to physiological constraints on their exclusion from those tissues. This pattern of secondary 461 metabolites restricted to non-vegetative plant parts is observed in other species. For example, in 462 Capsicum annuum, fruits and placenta contain capsaicin but vegetative parts do not (Iwai et al. 463 1979). In Piper reticulatum, seeds have the highest concentrations and chemical diversity of 464 amides compared to fruit pulp and leaves (Whitehead et al. 2013). And in Vaccinium macrocarpon, 465 ripe berries contain anthocyanin but unripe berries, leaves, stems, roots, and seeds do not (Zhou 466 and Singh 2002). The various classes of secondary metabolites likely play an adaptive role in 467 flowers and/or fruits, which experience complex and often conflicting selection pressures as they 468 serve to both attract mutualists (pollinators and seed dispersers) while deterring antagonists 469 (predators and pathogens; Cazetta et al. 2008, Kessler and Halitschke 2009).

470 Our results showing developmental variation in alkenylphenols uncover more detailed 471 information about the value and function of secondary metabolites. Of the three hypotheses posited 472 in this case study (manipulation of mutualists, defense allocated by attack, and defense allocated 473 by fitness), our results are consistent with the last. We found that fruit pulp had the highest 474 concentration of alkenylphenols, and the concentrations were allocated non-linearly across 475 ripening (increasing across development, then decreasing as fruit pulp ripened), which suggests 476 that the fitness consequences of tissue loss may be a better predictor of allocation patterns than 477 relative risk of attack (assuming the early developing tissues are indeed at higher risk of attack, 478 which has not been explicitly shown in this system). However, we cannot rule out the second non- 
adaptive hypothesis, where the reduction in the concentration of a compound during ripening could

480 be due to a non-adaptive enzymatic degradation that occurs during fruit softening (Brady 1987).

481 To explore this hypothesis, we would need to further understand the mechanisms behind the

482 reduction of alkenylphenols during ripening, including the processes involved, the ultimate fate of

483 the compounds, and any functional consequences of the products.

\section{Effects of alkenylphenols on fruit-associated fungi (antagonists)}

We found that alkenylphenols had clear antifungal activity against two (Fusarium A and

M. lycopodinum) of three fungal taxa, even at conservative doses relative to the concentrations

487 found in fruit pulp (Fig. 5). This suggests that fruit defense against fungal pathogens may be at

488 least one important function of alkenylphenols, similar to the role of other classes of secondary

489 metabolites found in high concentration in fruits (Haak et al. 2012, Whitehead and Bowers 2014).

490 Many fungal pathogens can destroy seeds, inhibit seed germination, and deter vertebrate seed

491 dispersers (Whittaker and Feeny 1971, Janzen 1977, Gallery et al. 2010); thus, defense of seeds

492 against fungi is critical for plant fitness. The fungal taxa used in our study were isolated from $P$.

493 sancti-felicis seeds. While this study did not directly test the pathogenic relationships between the

494 fungi and $P$. sancti-felicis, both fungal taxa have been documented in other systems as having

495 pathogenic properties (Tedersoo et al. 2014, Blacutt et al. 2018). Fusarium is a genus that is well

496 known for producing plant pathogens in many types of crops across ecosystems (Booth 1971,

497 Summerell 2019). For instance, Fusarium verticilloides can act as a seed-borne fungus in maize

498 (Zea mays), which causes seed, ear and stalk rot, among other seedling diseases (Marasas 2001).

499 While one of the most common Fusarium pathogens, Fusarium graminearum, damages the

500 reproductive structures of multiple different species of cereals and other crops in both temperate

501 and semi-tropical habitats (Goswami and Kistler 2004). Other species of Fusarium are known 
502 pathogens of Piper species: P. betle and P. nigrum (Shahnazi et al. 2012, Edward et al. 2013).

503 Furthermore, Microdochium is a common pathogen of grasses (Hernández-Restrepo et al. 2016),

504 but it can also act as a dark septate endophyte which colonizes the roots of grasses (Mandyam et

505 al. 2012). In an experimental inoculation with Microdochium as a dark septate endophyte, 506 colonization increased plant biomass or had no effect, depending on the species of grass (Mandyam

507 et al. 2012). Taken together, these studies suggest that Microdochium can be beneficial, 508 antagonistic, or have no effect on the host plant, depending on the context. Considering this 509 variation in the outcomes of plant-fungal interactions, further work is necessary to understand the 510 ultimate fitness consequences of antifungal alkenylphenols in Piper infructescences.

511 Given that one of our fungal taxa (Fusarium B) did not demonstrate a decline in growth 512 with concentration of alkenylphenols (Fig. 5), it is possible that it has evolved greater tolerance to 513 plant secondary metabolites that interfere with metabolism, which may be achieved through the 514 use of alternative energy production enzymes (Kerscher et al. 1999, Marcet-Houben et al. 2009, 515 O'Donnell et al. 2011). For instance, in the wild chili pepper (Capsicum chacoense), fungal 516 tolerance to dihydrocapsaicin was found in 16 fungal pathogens from four distantly related genera 517 (Alternaria, Colletotrichum, Fusarium and Phomopsis), which had alternative enzymes at 518 different stages of the electron transport chain such as for NADH dehydrogenase and oxidase 519 (Adams et al. 2019). Due to the phylogenetic breadth of this study, it suggests that alternative 520 mechanisms which allow fungal pathogens to tolerate capsaicinoids may be common (Adams et 521 al. 2019). Furthermore, it's interesting that one Fusarium taxon experienced a decline in growth 522 while the other taxon did not. This might be caused by variations in alternative metabolism 523 enzymes mentioned above, as this is a large genus which infects many different plant species. 524 Alternatively, Peris et al. (2017) found that fungal infestations can boost fruit odors, thereby 
525 increasing fruit removal by vertebrates. Thus, the fruit may be experiencing contradicting selective

526 pressures to protect against fungal competition of resources while maintaining fungi to attract

527 vertebrate seed dispersers.

528 Effects of alkenylphenols on seed dispersers (mutualists)

529 Our results suggest that alkenylphenols may also mediate $P$. sancti-felicis interactions with

530 seed dispersers. Most neotropical species of Piper are largely dispersed by bats (Fleming 2004),

531 but many species are also consumed extensively by birds (Palmeirim et al. 1989, Theis and Kalko

532 2004), or occasionally by other small mammals (Leiser-Miller et al. 2019) or ants (Thies and Kalko

533 2004, Clemente and Whitehead 2019). Our study expanded on the natural history knowledge of

534 seed dispersal in this system by quantifying nocturnal and diurnal fruit removal (Appendix S4:

535 Table S5) and further documented the community of birds that utilize $P$. sancti-felicis as a resource

536 (Appendix S4: Fig. S2). We found that $R$. passerini was the bird species found most often using

537 P. sancti-felicis plants, and a total of six bird species were observed eating the infructescences of

538 P. sancti-felicis (Appendix S4: Fig. S2). Field observations revealed a strong difference in the

539 amount and maturity of infructescences of $P$. sancti-felicis taken by nocturnal and diurnal animals.

540 Nocturnal consumers (presumably mostly bats) removed more infructescences and favored ripe

541 over unripe infructescences, whereas diurnal consumers (presumably mostly birds) removed fewer

542 infructescences and most were unripe (Appendix S4: Table S5). This makes sense considering our

543 experimental results showing that birds were less deterred by alkenylphenols, which are present in

544 higher concentrations in unripe fruit. A key unanswered question for determining the fitness

545 consequences of bird interactions with $P$. sancti-felicis is whether the seeds consumed in unripe

546 infructescences contain viable seeds that are dispersed intact following bird consumption. 
The stronger preference for ripe fruit in bats could also be in part due to alkenylphenol

548 content, which we found to be higher in unripe than in ripe fruit pulp (Fig. 4). Our disperser

549 preference trials indicated that alkenylphenol compounds decrease palatability but only for one

550 group of dispersers: bats (Fig. 7). A similar scenario has been shown in other systems, where birds

551 seem to have a higher threshold for secondary metabolites in fruits compared to small mammals

552 (Tewksbury and Nabhan 2001, but see Karasov et al. 2012). However, in this case the deterrent

553 effect is against the most frequent (and likely most effective) seed disperser. Quantifying the

554 fitness consequences of this deterrent effect would require extensive field studies to track seeds

555 and seedlings, but there are likely important costs associated with reduced bat preference. Even if

556 most infructescences are removed, infructescences containing high concentrations of deterrent

557 secondary metabolites could be rejected once bats begin to feed and dropped partially intact below

558 a feeding roost (as is the case with amides, Whitehead et al. 2016), where competition and

559 pathogen loads are likely high. In addition, less-preferred fruits may experience shorter dispersal

560 distances if they are removed later in the evening once the peak hours of bat activity have passed

561 (Baldwin et al. 2020). Thus, our overall findings are consistent with the defense trade-off

562 hypothesis (Cipollini and Levey 1997) — alkenylphenols may defend against fungi but have costs

563 associated with deterring an important group of seed dispersers. This scenario also provides a

564 parsimonious explanation for our results showing nonlinearity of alkenylphenol concentration

565 across development (Fig. 4) - the decrease upon ripening could be a product of selective pressure

566 exerted on fruit chemistry by bat feeding preference.

\section{Future directions}

568 In P. sancti-felicis, we were unable to definitively determine the double bond position and 569 stereochemistry of the doubly unsaturated components for four of the 10 alkenylphnols $(\mathrm{C}, \mathrm{D}, \mathrm{G}$, 
570 and $\mathrm{H}$ ). Future work may target the isolation and structure determination of the less abundant

571 components as they may also have important biological roles. Although our study provides a strong

572 foundation for understanding the ecological role of alkenylphenols in P. sancti-felicis, we cannot

573 definitively determine the raison d'etre of these compounds. They may have a wide spectrum of

574 potential functions (as seen with emodin; Izhaki 2002), and we did not address them all. To expand

575 upon the current knowledge and further address questions posed in this study, future work may

576 explore the potential multifunctionality of alkenylphenols for plants and how they improve plant

577 fitness. To address the other hypotheses put forth by Cipollini and Levey (1997), studies may

578 examine the effects of alkenylphenols on seed germination and establishment (seed germination

579 inhibition hypothesis) and on vertebrate disperser digestion (gut retention time hypothesis). We

580 determined that alkenylphenols are decreasing during ripening, but we did not determine the fate

581 of the alkenylphenols over the ripening process. Future studies may examine whether the decrease

582 in alkenylphenols across development is a result of biochemical activity, dilution, or translocation.

\section{Conclusions}

584 In this case study, we detail 10 previously undescribed alkenylphenol compounds in $P$.

585 sancti-felicis. We found that these alkenylphenols have greater concentrations and diversity in fruit

586 pulp and flowers when compared to leaves and seeds. Furthermore, the compound concentration

587 experiences a non-linear pattern across fruit development—increasing until fruit ripeness, when it

588 decreases. This uneven allocation of concentration and diversity in fruit pulp and flowers, with the

589 highest concentrations found in fruit pulp, suggests a role in fruit interactions. Although the

590 compounds are protecting against potential fungal pathogens, they deter important nocturnal seed

591 dispersers (bats). We suggest that these compounds are primarily defensive and allocated based on

592 the fitness cost of tissue consumption. We hope this research will serve as a roadmap for using 
593 intraplant allocation patterns to better understand the evolutionary ecology of plant chemical traits

594 and as a case study demonstrating the important roles of secondary metabolites in seed dispersal 595 and fruit defense.

ACKNOWLEDGEMENTS

We thank Orlando Vargas Ramírez, Danilo Brenes Madrigal, Joel Alvarado, Danielle

599 Salcido, and Bernadette Rigley for their assistance at La Selva Biological Station. We thank Sherri

600 Maynard for her illustrations. Funding for the chemical isolation and analysis was provided by the

601 Hitchcock Center for Chemical-Ecology at UNR and the National Science Foundation (DEB-

6021145609 and DEB-1442103). We thank Jennifer L. McCracken for her assistance with the

603 collection of the alkenylphenol spectroscopic data. Quantification of alkenylphenols at Virginia

604 Tech was partially supported by NSF Grant DEB-1856766 to SRW. LDM was supported by a

605 National Science Foundation Graduate Research Fellowship, OTS Graduate Research

606 Fellowships, and Virginia Polytechnic Institute and State University, including start-up funds to

607 SRW and the Graduate Student Assembly Graduate Research Development Program. HLS was

608 supported by a Natural Sciences and Engineering Research Council Post-Graduate Doctoral

609 Scholarship, the Mycological Association of America Backus Award, and the College of

610 Biological Science at the University of Guelph.

611

612

613 Adams, C. A., K. Zimmerman, K. Fenstermacher, M. G. Thompson, W. Skyrud, S. Behie, and

614 A. Pringle. 2019. Fungal seed pathogens of wild chili peppers possess multiple

615 mechanisms to tolerate capsaicinoids. Applied and Environmental Microbiology

$616 \quad 86: \mathrm{e} 01697-19$. 
617 Altschul, S. F., W. Gish, W. Miller, E. W. Myers, and D. J. Lipman. 1990. Basic local alignment 618 search tool. Journal of Molecular Biology 215:403-410.

619 Baldwin, J. W., D. K. N. Dechmann, W. Thies, and S. R. Whitehead. 2020. Defensive fruit 620 metabolites obstruct seed dispersal by altering bat behavior and physiology at multiple $621 \quad$ temporal scales. Ecology 101:e02937.

622 Baldwin, J. W., and S. R. Whitehead. 2015. Fruit secondary compounds mediate the retention 623 time of seeds in the guts of neotropical fruit bats. Oecologia 177:453-466.

624 Barnea, A., J. B. Harborne, and C. Pannell. 1993. What parts of fleshy fruits contain secondary compounds toxic to birds and why? Biochemical Systematics and Ecology 21:421-429.

Barton, K. E., K. F. Edwards, and J. Koricheva. 2019. Shifts in woody plant defence syndromes during leaf development. Functional Ecology 33:2095-2104.

Beckman, N. G. 2013. The distribution of fruit and seed toxicity during development for eleven neotropical trees and vines in central Panama. PLoS ONE 8:e66764.

Blacutt, A. A., S. E. Gold, K. A. Voss, M. Gao, and A. E. Glenn. 2018. Fusarium verticillioides : advancements in understanding the toxicity, virulence, and niche adaptations of a model mycotoxigenic pathogen of maize. Phytopathology 108:312-326.

633 Booth, C. 1971. The genus Fusarium. Commonwealth Mycological Institute, Kew, Surrey, UK.

634 Brady, C. J. 1987. Fruit ripening. Annual Review of Plant Physiology 38:155-178.

635 Cappelletti, E. M., G. Innocenti, and G. Caporale. 1992. Possible ecological significance of 636 within-fruit and seed furocoumarin distribution in two Psoralea species. Journal of Chemical Ecology 18:155-164.

638 Cazetta, E., H. M. Schaefer, and M. Galetti. 2008. Does attraction to frugivores or defense 639 against pathogens shape fruit pulp composition? Oecologia 155:277-286. 
Charles-Dominique, P. 1986. Inter-relations between frugivorous vertebrates and pioneer plants: Cecropia, birds and bats in French Guyana. Pages 119-135 in A. Estrada and T. H. Fleming, editors. Frugivores and seed dispersal. Springer Netherlands, Dordrecht.

Cipollini, M. L. 2000. Secondary metabolites of vertebrate-dispersed fruits: evidence for adaptive functions. Revista Chilena de Historia Natural 73:421-440.

Cipollini, M. L., and D. J. Levey. 1997. Secondary metabolites of fleshy vertebrate-dispersed fruits: adaptive hypotheses and implications for seed dispersal. The American Naturalist $150: 346-372$.

Clemente, S. R., and S. R. Whitehead. 2019. Ant seed removal in a non-myrmecochorous neotropical shrub: Implications for seed dispersal. Biotropica 00:1-11.

D’Abrosca, B., M. Lavorgna, M. Scognamiglio, C. Russo, V. Graziani, C. Piscitelli, A. Fiorentino, and M. Isidori. 2017. 2D-NMR investigation and in vitro evaluation of antioxidant, antigenotoxic and estrogenic/antiestrogenic activities of strawberry grape. Food and Chemical Toxicology 105:52-60.

Dyer, L. A., C. D. Dodson, J. Beihoffer, and D. K. Letourneau. 2001. Trade-offs in antiherbivore defenses in Piper cenocladum: ant mutualists versus plant secondary metabolites. Journal of Chemical Ecology 27:581-592.

Dyer, L. A., J. Richards, and C. D. Dodson. 2004. Isolation, synthesis, and evolutionary ecology of Piper amides. Pages 117-139 in L. A. Dyer and A. D. N. Palmer, editors. Piper: a model genus for studies of phytochemistry, ecology, and evolution. Kluwer Academic/Plenum Publishers, New York, NY.

Edward, E. J., W. S. King, S. L. C. Teck, M. Jiwan, Z. F. A. Aziz, F. R. Kundat, O. H. Ahmed, and N. M. A. Majid. 2013. Antagonistic activities of endophytic bacteria against 
Fusarium wilt of black pepper (Piper nigrum). International Journal of Agriculture and Biology 15:291-296.

Eriksson, O., and J. Ehrlén. 1998. Phenological adaptations in fleshy vertebrate-dispersed fruits of temperate plants. Oikos 82:617-621.

Fleming, T. H. 2004. Dispersal ecology of neotropical Piper shrubs and treelets. Pages 58-77 in L. A. Dyer and A. D. N. Palmer, editors. Piper: a model genus for studies of phytochemistry, ecology, and evolution. First edition. Kluwer Academic/Plenum Publishers, New York, NY.

671 Fox, J., S. Weisberg, B. Price, D. Adler, D. Bates, G. Baud-Bovy, B. Bolker, S. Ellison, D. Firth, M. Friendly, G. Gorjanc, S. Graves, R. Heiberger, P. Krivitsky, R. Laboissiere, M. Maechler, G. Monette, D. Murdoch, H. Nilsson, D. Ogle, B. Ripley, W. Venables, S. Walker, D. Winsemius, A. Zeileis, and R-Core. 2019. car: Companion to applied regression.

Fujiwake, H., T. Suzuki, and K. Iwai. 1982. Intracellular distributions of enzymes and intermediates involved in biosynthesis of capsaicin and its analogues in Capsicum fruits. Agricultural and Biological Chemistry 46:2685-2689.

Galinis, D. L., and D. F. Wiemer. 1993. Villiramulins A and B: new phenol derivatives from Piper villiramulum. The Journal of Organic Chemistry 58:7804-7807.

Gallery, R. E., D. J. P. Moore, and J. W. Dalling. 2010. Interspecific variation in susceptibility to fungal pathogens in seeds of 10 tree species in the neotropical genus Cecropia. Journal of Ecology 98:147-155.

685 Goswarmi, R. S., and H. C. Kistler. 2004. Heading for disaster: Fusarium graminearum on 
cereal crops. Molecular Plant Pathology 5:515-525.

Greig, N. 2004. Introduction. Page in L. A. Dyer and A. D. N. Palmer, editors. Piper: a model genus for studies of phytochemistry, ecology, and evolution. Kluwer Academic/Plenum

Haak, D. C., L. A. Mcginnis, D. J. Levey, and J. J. Tewksbury. 2012. Why are not all chilies hot? A trade-off limits pungency. Proceedings of the Royal Society B: Biological Sciences 279:2012-2017.

Hall, R. D., M. A. Holden, and Michael. M. Yeoman. 1987. The accumulation of phenylpropanoid and capsaicinoid compounds in cell cultures and whole fruit of the chilli

Iwai, K., T. Suzuki, and H. Fujiwake. 1979. Formation and accumulation of pungent principle of hot pepper fruits, capsaicin and its analogues, in Capsicum annuun var. annuun cv.

Izhaki, I. 2002. Emodin: a secondary metabolite with multiple ecological functions in higher Karayatsubusa at different growth stages after flowering. Agricultural and Biological plants. The New Phytologist 155:205-217. 111:691-713. 2012. Capacity for absorption of water-soluble secondary metabolites greater in birds than in rodents. PLoS ONE 7:e32417. 
Kerscher, S. J., J. G. Okun, and U. Brandt. 1999. A single external enzyme confers alternative NADH:ubiquinone oxidoreductase activity in Yarrowia lipolytica. Journal of Cell Science 112:2347-2354.

712 Kessler, A., and R. Halitschke. 2009. Testing the potential for conflicting selection on floral

Kessler, A., and A. Kalske. 2018. Plant secondary metabolite diversity and species interactions. Annual Review of Ecology, Evolution, and Systematics 49:115-138.

Kõljalg, U., K.-H. Larsson, K. Abarenkov, R. H. Nilsson, I. J. Alexander, U. Eberhardt, S. Erland, K. Høiland, R. Kjøller, E. Larsson, T. Pennanen, R. Sen, A. F. S. Taylor, L. Tedersoo, and T. Vrålstad. 2005. UNITE: a database providing web-based methods for the molecular identification of ectomycorrhizal fungi. New Phytologist 166:1063-1068.

Kolniak-Ostek, J. 2016. Chemical composition and antioxidant capacity of different anatomical parts of pear (Pyrus communis L.). Food Chemistry 203:491-497.

Kulkarni, A. 2005. Chemical changes and antioxidant activity in pomegranate arils during fruit development. Food Chemistry 93:319-324.

Kursar, T. A., and P. D. Coley. 1991. Nitrogen content and expansion rate of young leaves of rain forest species: implications for herbivory. Biotropica 23:141-150.

Leiser-Miller, L. B., Z. A. Kaliszewska, D. Villalobos-Chaves, and S. E. Santana. 2019. A pygmy rice rat eats a peppery snack. Frontiers in Ecology and the Environment 17:369369.

Lenth, R., H. Singmann, J. Love, P. Buerkner, and M. Herve. 2019. emmeans: estimated marginal means, aka least-squares means. 
732 Levey, D. J. 1987. Seed size and fruit-handling techniques of avian frugivores. The American $733 \quad$ Naturalist 129:471-485.

734 Linden, M. J. M. and portions of code contributed by D. 2019. AICcmodavg: model selection 735 and multimodel inference based on (Q)AIC(c).

736 Mandyam, K., C. Fox, and A. Jumpponen. 2012. Septate endophyte colonization and host responses of grasses and forbs native to a tallgrass prairie. Mycorrhiza 22:109-119.

738 Marasas, W. F. O. 2001. Discovery and occurrence of the fumonisins: a historical perspective. 739 Environmental Health Perspectives 109:239-243.

740 Marcet-Houben, M., G. Marceddu, and T. Gabaldón. 2009. Phylogenomics of the oxidative phosphorylation in fungi reveals extensive gene duplication followed by functional divergence. BMC Evolutionary Biology 9:295.

743 Maynard, L. D., A. Ananda, M. F. Sides, H. Burk, and S. R. Whitehead. 2019. Dietary resource overlap among three species of frugivorous bat in Costa Rica. Journal of Tropical Ecology 35:165-172.

McCall, A. C., and J. A. Fordyce. 2010. Can optimal defence theory be used to predict the distribution of plant chemical defences? Journal of Ecology 98:985-992.

Moore, B. D., R. L. Andrew, C. Külheim, and W. J. Foley. 2014. Explaining intraspecific diversity in plant secondary metabolites in an ecological context. New Phytologist 201:733-750.

751 Nguyen, N. H., Z. Song, S. T. Bates, S. Branco, L. Tedersoo, J. Menke, J. S. Schilling, and P. G. Kennedy. 2016. FUNGuild: an open annotation tool for parsing fungal community datasets by ecological guild. Fungal Ecology 20:241-248.

754 Nilsson, R. H., K.-H. Larsson, A. F. S. Taylor, J. Bengtsson-Palme, T. S. Jeppesen, D. Schigel, 
P. Kennedy, K. Picard, F. O. Glöckner, L. Tedersoo, I. Saar, U. Kõljalg, and K. Abarenkov. 2019. The UNITE database for molecular identification of fungi: handling dark taxa and parallel taxonomic classifications. Nucleic Acids Research 47:D259-D264.

758 Nilsson, R. H., M. Ryberg, E. Kristiansson, K. Abarenkov, K.-H. Larsson, and U. Kõljalg. 2006.

759 Taxonomic reliability of DNA sequences in public sequence databases: a fungal $760 \quad$ perspective. PLoS ONE 1:e59.

761 O’Donnell, A., L. M. Harvey, and B. McNeil. 2011. The roles of the alternative NADH niger. Fungal Biology 115:359-369.

764 de Oliveira, A., J. T. Mesquita, A. G. Tempone, J. H. G. Lago, E. F. Guimarães, and M. J. Kato. 765 2012. Leishmanicidal activity of an alkenylphenol from Piper malacophyllum is related 766 to plasma membrane disruption. Experimental Parasitology 132:383-387.

767 Orjala, J., P. Mian, T. Rali, and O. Sticher. 1998. Gibbilimbols A-D, cytotoxic and antibacterial 768 alkenylphenols from Piper gibbilimbum. Journal of Natural Products 61:939-941.

769 OTS. 2020. Organization for Tropical Studies database: la flora digital de La Selva. https://sura.ots.ac.cr/florula4/.

771 Palmeirim, J. M., D. L. Gorchov, and S. Stoleson. 1989. Trophic structure of a neotropical frugivore community: is there competition between birds and bats? Oecologia 79:403-

774 Peris, J. E., A. Rodríguez, L. Penã, and J. M. Fedriani. 2017. Fungal infestation boosts fruit 775 aroma and fruit removal by mammals and birds. Scientific Reports 7:1-9. Statistical Computing. Vienna, Austria. 
Rodríguez, A., B. Alquézar, and L. Peña. 2013. Fruit aromas in mature fleshy fruits as signals of readiness for predation and seed dispersal. New Phytologist 197:36-48.

Schoch, C. L., K. A. Seifert, S. Huhndorf, V. Robert, J. L. Spouge, C. A. Levesque, W. Chen, and F. B. Consortium. 2012. Nuclear ribosomal internal transcribed spacer (ITS) region as a universal DNA barcode marker for Fungi. Proceedings of the National Academy of Sciences 109:6241-6246.

Schupp, E. W., P. Jordano, and J. M. Gómez. 2010. Seed dispersal effectiveness revisited: a conceptual review. New Phytologist 188:333-353.

Shahnazi, S., S. Meon, G. Vadamalai, K. Ahmad, and N. Nejat. 2012. Morphological and molecular characterization of Fusarium spp. associated with yellowing disease of black pepper (Piper nigrum L.) in Malaysia. Journal of General Plant Pathology 78:160-169.

Summerell, B. A. 2019. Resolving Fusarium: current status of the genus. Annual Review of Phytopathology 57:323-339.

Swain, T. 1977. Secondary compounds as protective agents. Annual Review of Plant Physiology 28:479-501.

Tedersoo, L., M. Bahram, S. Polme, U. Koljalg, N. S. Yorou, R. Wijesundera, L. V. Ruiz, A. M. Vasco-Palacios, P. Q. Thu, A. Suija, M. E. Smith, C. Sharp, E. Saluveer, A. Saitta, M. Rosas, T. Riit, D. Ratkowsky, K. Pritsch, K. Poldmaa, M. Piepenbring, C. Phosri, M. Peterson, K. Parts, K. Partel, E. Otsing, E. Nouhra, A. L. Njouonkou, R. H. Nilsson, L. N. Morgado, J. Mayor, T. W. May, L. Majuakim, D. J. Lodge, S. S. Lee, K.-H. Larsson, P. Kohout, K. Hosaka, I. Hiiesalu, T. W. Henkel, H. Harend, L. -d. Guo, A. Greslebin, G. Grelet, J. Geml, G. Gates, W. Dunstan, C. Dunk, R. Drenkhan, J. Dearnaley, A. De Kesel, T. Dang, X. Chen, F. Buegger, F. Q. Brearley, G. Bonito, S. Anslan, S. Abell, and 

346:1256688-1256688.

803 Tewksbury, J. J. 2002. Fruits, frugivores and the evolutionary arms race. New Phytologist 156:137-139.

Tewksbury, J. J., and G. P. Nabhan. 2001. Directed deterrence by capsaicin in chillies. Nature 412:403-404.

Thies, W., and E. K. V. Kalko. 2004. Phenology of neotropical pepper plants (Piperaceae) and their association with their main dispersers, two short-tailed fruit bats, Carollia perspicillata and C. castanea (Phyllostomidae). Oikos 104:362-376.

Thies, W., E. K. V. Kalko, and H.-U. Schnitzler. 1998. The roles of echolocation and olfaction in two neotropical fruit-eating bats, Carollia perspicillata and C. castanea, feeding on Piper. Behavioral Ecology and Sociobiology 42:397-409.

816 Valdivia, C., N. Marquez, J. Eriksson, A. Vilaseca, E. Muñoz, and O. Sterner. 2008. Bioactive alkenylphenols from Piper obliquum. Bioorganic and Medicinal Chemistry 16:4120-

Varela, M. T., M. L. Lima, M. K. Galuppo, A. G. Tempone, A. de Oliveira, J. H. G. Lago, and J. P. S. Fernandes. 2017. New alkenyl derivative from Piper malacophyllum and analogues: antiparasitic activity against Trypanosoma cruzi and Leishmania infantum. Chemical

823 Vieira, P. C., M. A. D. Alvarenga, O. R. Gottlieb, and H. E. Gottlieb. 1980. 4- 

Hexadecenylphenol and flavonoids from Piper hispidum. Planta Medica 39:153-156.

825 Whitehead, S. R., and M. D. Bowers. 2013. Evidence for the adaptive significance of secondary 826 compounds in vertebrate-dispersed fruits. The American Naturalist 182:563-577.

827 Whitehead, S. R., and M. D. Bowers. 2014. Chemical ecology of fruit defence: synergistic and 828

Whittaker, R. H., and P. P. Feeny. 1971. Allelochemics: chemical interactions between species. antagonistic interactions among amides from Piper. Functional Ecology 28:1094-1106.

Whitehead, S. R., C. S. Jeffrey, M. D. Leonard, C. D. Dodson, L. A. Dyer, and M. D. Bowers. 2013. Patterns of secondary metabolite allocation to fruits and seeds in Piper reticulatum.

Whitehead, S. R., M. F. Obando-Quesada, and M. D. Bowers. 2016. Chemical tradeoffs in seed dispersal: defensive metabolites in fruits deter consumption by mutualist bats. Oikos 125:927-937. Science 171:757-770.

Wickham, H., W. Chang, L. Henry, T. L. Pedersen, K. Takahashi, C. Wilke, K. Woo, H. Yutani, and RStudio. 2019. ggplot2: create elegant data visualisations using the grammar of graphics.

Yang, S.-X., Q.-Y. Sun, F.-M. Yang, G.-W. Hu, J.-F. Luo, Y.-H. Wang, and C.-L. Long. 2013. Sarmentosumols A to F, new mono- and dimeric alkenylphenols from Piper sarmentosum. Planta Med 79:693-696.

Yoshida, N. C., A. M. Benedetti, R. A. dos Santos, C. S. Ramos, R. Batista, L. F. Yamaguchi, and M. J. Kato. 2018. Alkenylphenols from Piper dilatatum and P. diospyrifolium. Phytochemistry Letters 25:136-140.

Zeileis, A., F. Cribari-Neto, B. Gruen, I. Kosmidis, A. B. S. (earlier version by), and A. V. R. 
(earlier version by). 2019. betareg: beta regression.

848 Zgoda, J. R., and J. R. Porter. 2001. A convenient microdilution method for screening natural

849 products against bacteria and fungi. Pharmaceutical Biology 39:221-225.

850 Zhang, Y., P. Li, and L. Cheng. 2010. Developmental changes of carbohydrates, organic acids,

851 amino acids, and phenolic compounds in 'Honeycrisp' apple flesh. Food Chemistry

$852 \quad 123: 1013-1018$.

853 Zhou, Y., and B. R. Singh. 2002. Red light stimulates flowering and anthocyanin biosynthesis in 854 American cranberry. Plant Growth Regulation 38:165-171. 
Table 1. Hypothesized patterns of secondary metabolite concentrations during fruit development.

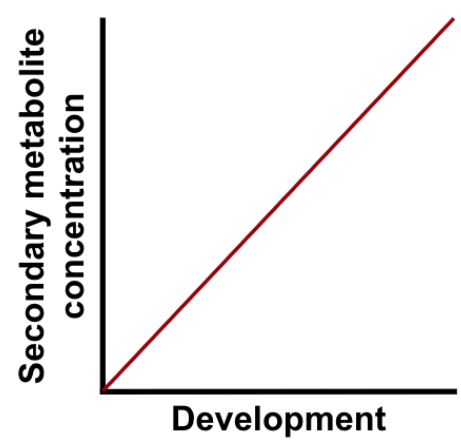

Increasing linear Manipulation of mutualists

Hypothesized function:

Secondary metabolites function in ripe fruits to manipulate mutualists and increase the effectiveness of dispersal services. Thus, the concentration is highest in fully developed fruit that is ready to be dispersed from the parent plant.

Predicted trend: Secondary metabolites increase linearly with fruit development.
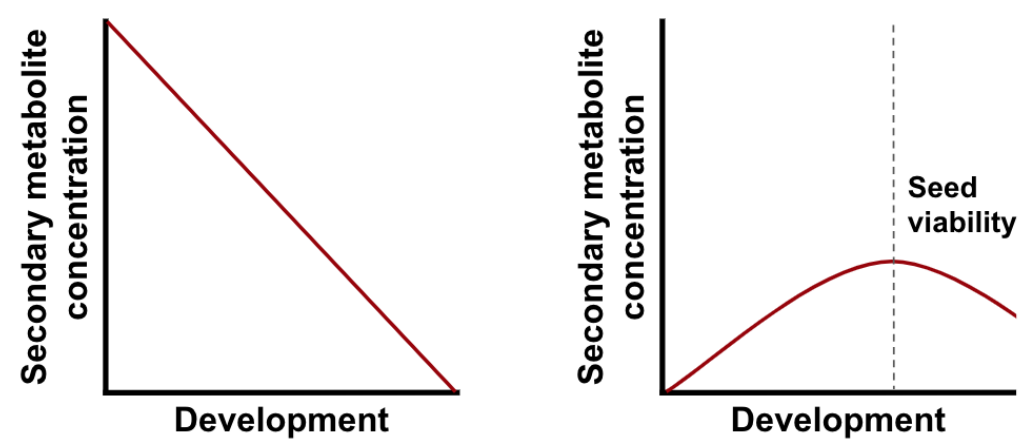

\section{Decreasing linear \\ Defense: allocated by risk}

Hypothesized function:

Secondary metabolites function

in unripe fruits to defend

against antagonists and are

allocated according to risk of attack. Thus, the concentration is highest in young tissues that are not yet physically defended.

Predicted trend: Secondary metabolites decrease linearly with fruit development.
Nonlinear

Defense: allocated by fitness

Hypothesized function:

Secondary metabolites function in unripe fruits to defend against antagonists and are allocated according to fitness consequences of consumption. Thus, the concentration is highest just prior to seed maturity when the fitness costs of loss would be highest.

Predicted trend: Secondary metabolites increase initially with development then decrease as fruits ripen. 


\section{FIGURE LEGENDS}

Figure 1. Piper sancti-felicis reproductive structures developing successively along a branch. From left to right: developing inflorescence, two inflorescences, two unripe infructescences, and one ripe infructescence. Illustration by Sherri Maynard.

Figure 2. Secondary metabolites (alkenylphenols) isolated from the infructescences of Piper sancti-felicis (A-J).

Figure 3. Alkenylphenol concentration (proportion dry weight) differed across plant tissues. Pulp, including ripe and late unripe, had higher concentrations of alkenylphenols compared to all other tissue types. Late flowers had higher concentrations than leaves and seeds. Box margins indicate the 25th and 75th percentiles, whiskers the 5th and 95th percentiles, solid lines within the boxes the median, and points individual data observations of total alkenylphenol concentrations from $N=21$ plants. Letters indicate significant differences from post-hoc pairwise comparisons among tissue types. Ripe pulp $(N=20)$, late unripe pulp $(N=21)$, late flowers $(N=21)$, mature leaves $(N=4)$, and seeds $(N=6)$.

Figure 4. The concentration of alkenylphenols follows a nonlinear trend over reproductive structure stage of development that peaks just before ripening. Stage of development $(z=2.27, P$ $=0.023$; beta regression) was significant in predicting alkenylphenol concentration. Colored lines are individual plants, and the bold black line is the nonlinear fit of the data with the gray band indicating 95\% confidence intervals. Ripe pulp $(N=20)$, late unripe pulp $(N=21)$, early 
unripe pulp $(N=19)$, late flowers $(N=21)$, early flowers $(N=15)$, and developing flowers $(N=11)$. Concentrations of alkenylphenols calculated as internal standard equivalents ( $\mathrm{mg} / \mathrm{ml})$.

Figure 5. The effect of alkenylphenols on hyphal growth of three types of fungi harvested from unsterilized seeds of Piper sancti-felicis. Hyphal growth was measured as the difference in optical density (or absorbance) at $72 \mathrm{~h}$ minus $0 \mathrm{~h}$. Points are individual observations, lines are linear fits of the data with gray bands indicating 95\% confidence intervals. Alkenylphenols had antifungal effects for two of the three naturally occurring fungi (Fusarium A and Microdochium lycopodinum) but not Fusarium B. Concentrations of alkenylphenols are estimated as internal standard equivalents $(\mathrm{mg} / \mathrm{ml})$.

Figure 6. Overall effect of alkenylphenols on bat (Carollia perspicillata; a) and bird (Ramphocelus passerinii; b) feeding responses. Treatment diets contained approximately 14.6 mg infructescence-extracted alkenylphenols in $3 \mathrm{~g}$ of diet, a concentration that mimicked the average concentration found in a ripe infructescence of $P$. sancti-felicis $(0.0049$ proportion wet weight). Amount of control and treatment diets eaten were averaged for each individual (bats $N=$ 16 , birds $N=10$ ) for all trials (bat trials $N=58$, bird trials $N=27$ ). Alkenylphenols had a negative effect on bat feeding response $(t=2.20, d f=15, P=0.044$; paired t-test $)$ but no detectable effect on birds $(t=0.26, d f=9, P=0.80$; paired t-test $)$. Bats consumed an average of 2.4 times more control than treatment, whereas birds only consumed an average of 1.1 times more control than treatment. Box and whisker plots show the median, 25th and 75th percentile, and range of average amount of each dish consumed, and points are the average amount consumed across trials for each individual. 
Figure 1

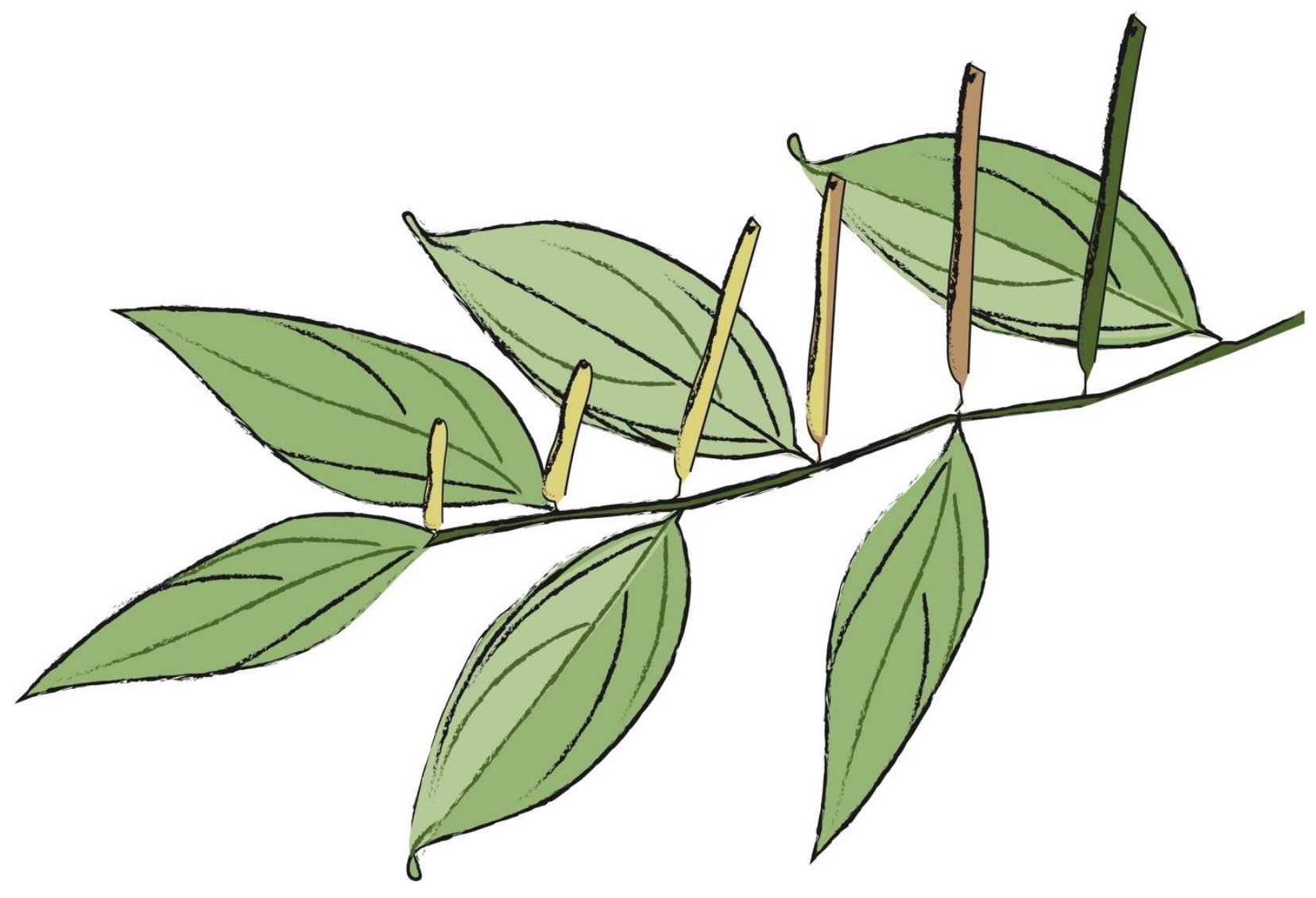


Figure 2

(1)

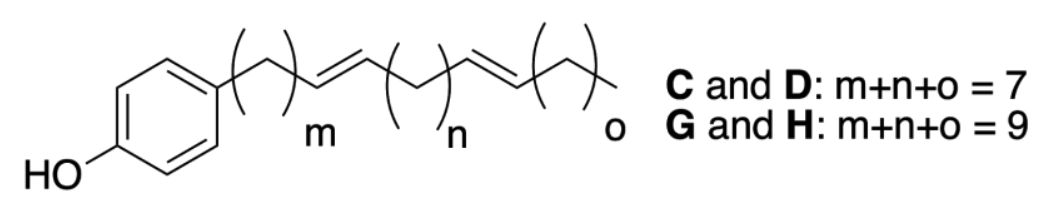


Figure 3

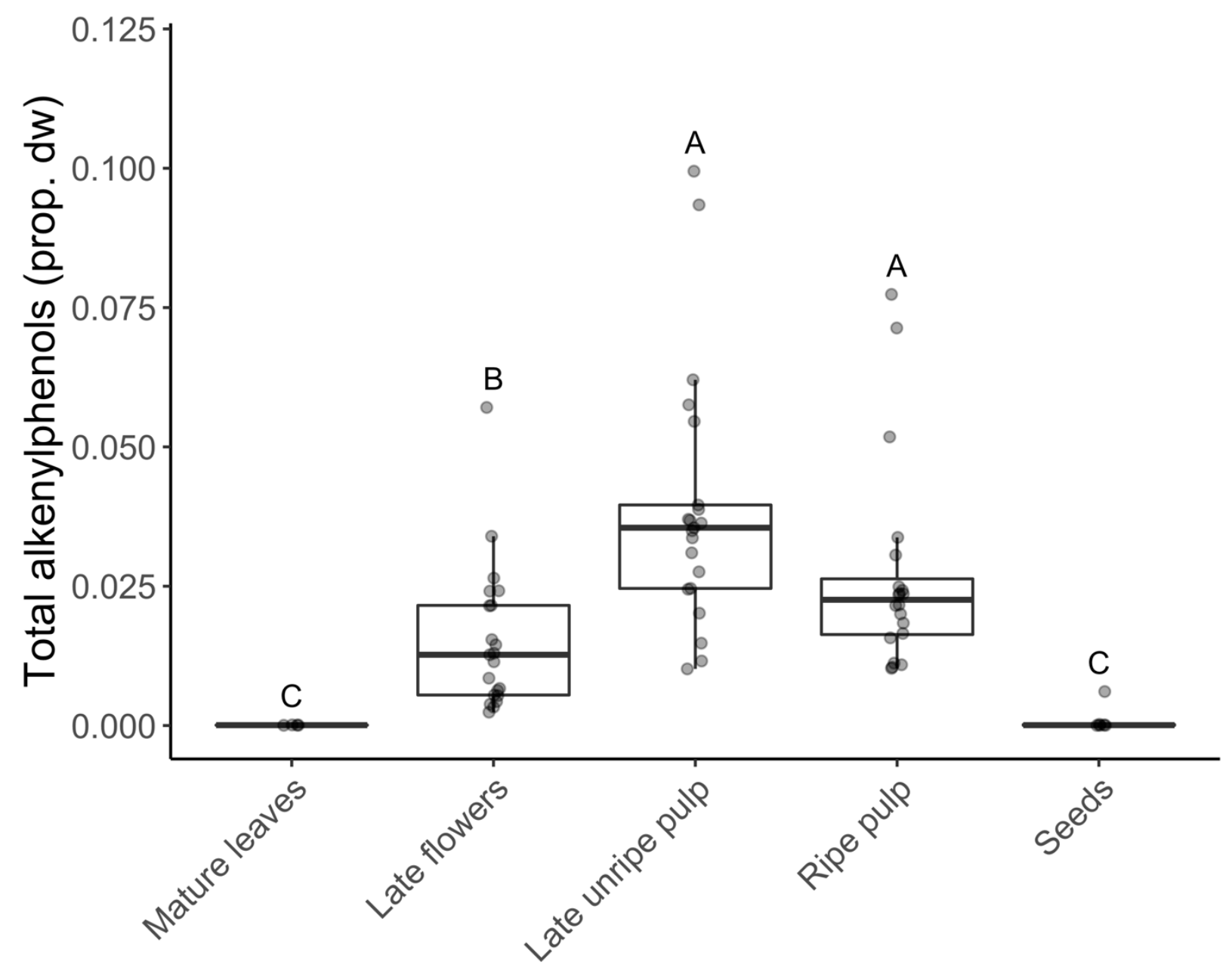




\section{Figure 4}

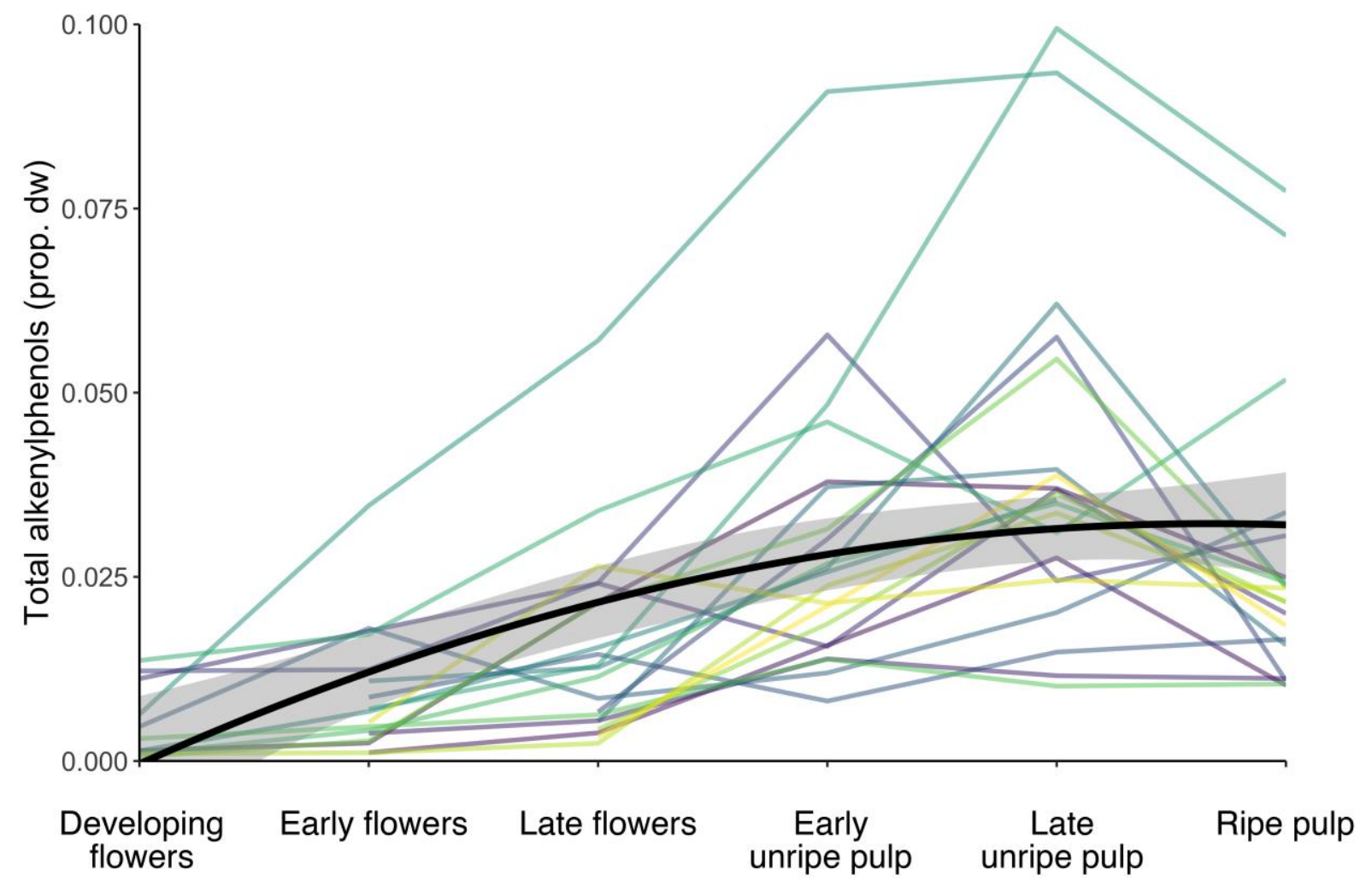


Figure 5

$\rightarrow$ Fusarium A $\rightarrow$ Fusarium B $\square$ Microdochium lycopodinum

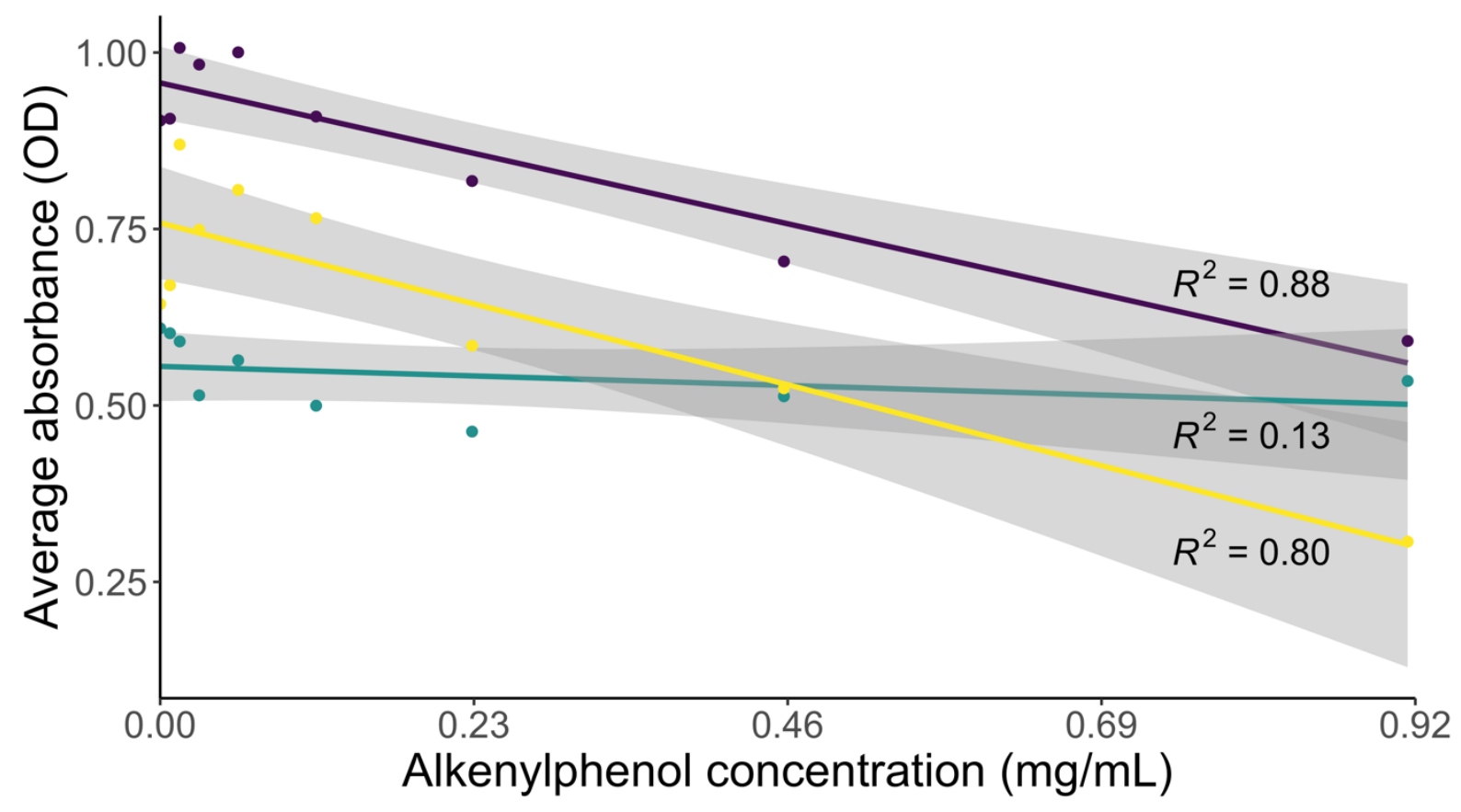


Figure 6
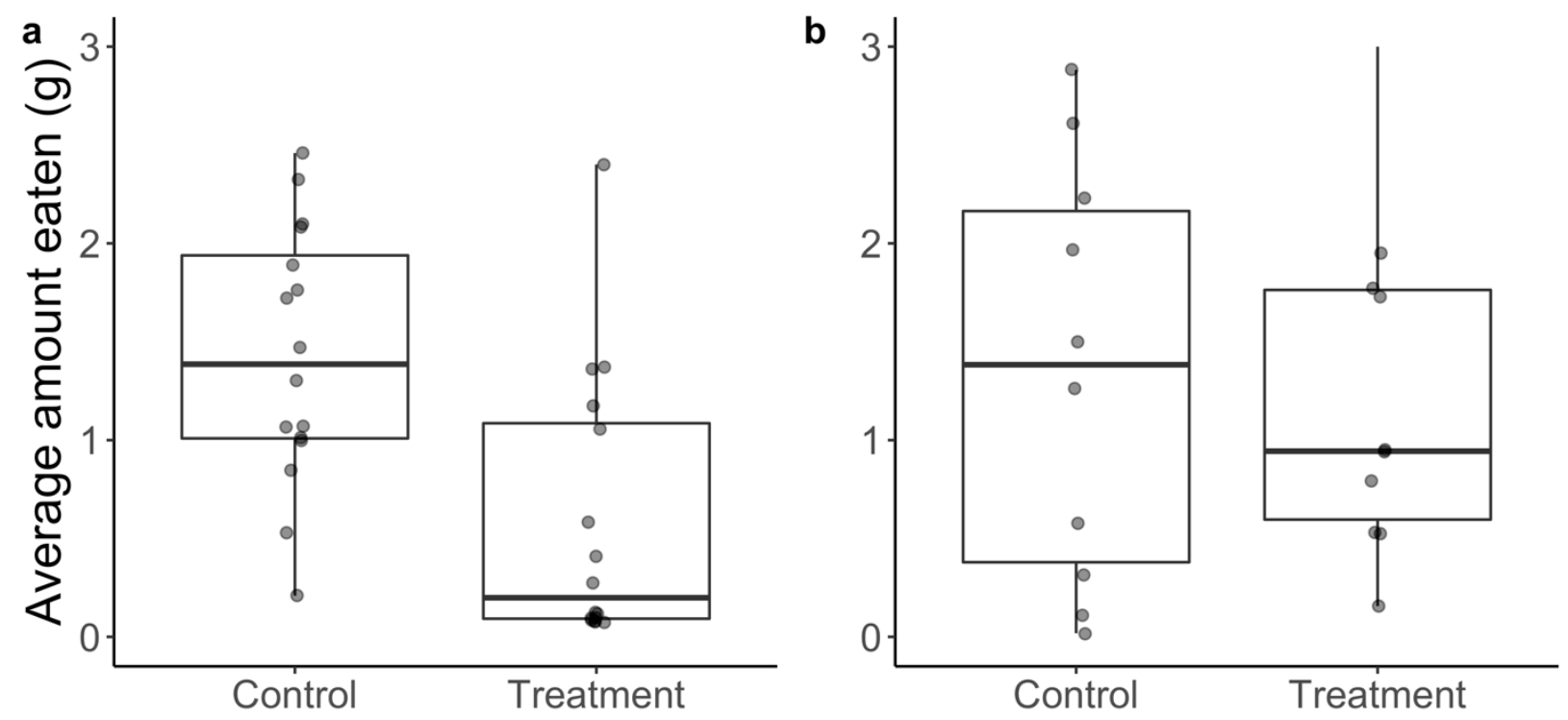